\title{
ARTICLE
}

\section{Focus on adolescents with HIV and AIDS}

\author{
L Fairlie, ${ }^{1} \mathrm{MB}$ ChB, DCH (UK), FCPaed (SA), MMed; N Sipambo, ${ }^{1,2}$ MB BCh, FCPaed (SA); \\ C Fick, ${ }^{1} \mathrm{MB}$ BCh, Dip HIV Man; H Moultrie, ${ }^{1} \mathrm{MB}$ BCh, MSc \\ ${ }^{1}$ Wits Reproductive Health and HIV Institute (WRHI), University of the Witwatersrand, Johannesburg, South Africa \\ ${ }^{2}$ Department of Paediatrics, Chris Hani Baragwanath Hospital, Faculty of Health Sciences, University of the Witwatersrand, \\ Johannesburg, South Africa
}

Corresponding author: L Fairlie (lfairlie@wrhi.ac.za)

\begin{abstract}
Adolescents living with HIV, including those infected perinatally and non-perinatally, bear a disproportionate burden of the HIV epidemic in South Africa. This article discusses HIV management in adolescents including the following aspects: (i) burden of HIV disease, modes of HIV acquisition and implications for management; (ii) initiation of combination antiretroviral therapy (ART), outcomes and complications of ART in adolescents, including virological failure and switching regimens; (iii) adherence in adolescence, including factors that may contribute to poor adherence and advice to improve adherence; (iv) issues particular to adolescents, including sexual and reproductive health needs, disclosure to adolescents and by adolescents, and transition to adult care. This article aims to provide insights based on the literature and experience to assist the clinician to navigate the difficulties of managing HIV in adolescence and achieving successful transition to adult care.
\end{abstract}

S Afr Med J 2014;104(12):897. DOI:10.7196/SAMJ.9110

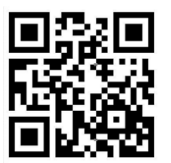

Epidemiology

There are few routine data on the health of South African (SA) adolescents (defined by the World Health Organization (WHO) as aged 10 - 19 years), partly a result of the age bands used in the District Health Information System. This is cause for concern. Many of the determinants of adult ill health, such as harmful alcohol use, tobacco use, unhealthy diet, and lack of physical activity, have their origins in adolescence. Critically, female adolescents bear a disproportionate burden of the HIV epidemic in SA. In 2012, the estimated HIV prevalence (range) in 15 - 24-year-old SA women and men was $13.9 \%$ (12.9 $16.8 \%)$ and $3.9 \%(2.5-5.7 \%)$, respectively, ${ }^{[1]}$ equating to $\sim 720000$ adolescents and young people living with $\mathrm{HIV}^{[2]}$ The population of adolescents living with HIV in SA is comprised of adolescents with perinatal HIV infection (PHIV) who have moved into adolescence (PHIA) and those who acquired HIV at an older age through sexual activity, intravenous drug use or other less common modes of transmission (non-PHIV).

The prevention of mother-to-childtransmission programme (PMTCT) in SA has led to a massive reduction in perinatal HIV infections in the last decade. As a result, combined with high coverage and early initiation of combination antiretroviral therapy (ART) with concomitant reductions in morbidity and mortality, the SA population of children with perinatally acquired HIV is rapidly moving into adolescence, with adolescents possibly already forming the bulk of paediatric HIV patients. ${ }^{[3]}$ Some PHIA will have been diagnosed with HIV and started on ART early in childhood, with some already on secondor third-line ART by the time they reach adolescence. Other PHIA who are diagnosed in late childhood or in early to mid-adolescence are often severely immunocompromised and urgently require ART at the time of diagnosis, though up to half may be asymptomatic. ${ }^{[4]}$ These late presenters represent ongoing missed diagnostic opportunities, the result of numerous factors beyond the scope of this article, but which include poor record keeping contributing to subtle chronic symptoms not being appropriately identified or investigated by healthcare workers despite numerous clinic visits, and the lack of child- or youth-friendly services hampering accessibility.

The prevention and diagnosis of HIV infection acquired in adolescence continues

Table 1. Criteria for ART initiation in ALHIV

\begin{tabular}{|c|c|}
\hline Criteria for initiation of ART in ALHIV & $\begin{array}{l}\text { Criteria for fast-tracking (starting ART within } \\
7 \text { days of being eligible) }\end{array}$ \\
\hline WHO stage 3 or 4 & $\mathrm{CD} 4^{+}$count of $\leq 200$ cells $/ \mathrm{mm}^{3}$ \\
\hline \multirow[t]{3}{*}{$\mathrm{CD} 4^{+}$count $\leq 500$ cells $/ \mathrm{mm}^{3}$} & WHO stage 4 disease \\
\hline & $\begin{array}{l}\text { Pregnancy or breastfeeding (PMTCT started } \\
\text { urgently) }\end{array}$ \\
\hline & MDR/XDR-TB \\
\hline
\end{tabular}

to require urgent attention. Nearly a quarter (24\%) of all new HIV infections in SA in 2012 occurred in 15 - 24-year-olds, with the incidence in women in this age group almost 4 times greater than that in men $(2.5 \% \mathrm{v}$. 0.6\%). ${ }^{[2]}$ Adolescents living with HIV acquired during adolescence are likely to have earlystage disease, higher $\mathrm{CD} 4^{+}$counts, and fewer opportunistic infections, and are less likely to meet current criteria for initiation of ART than PHIA. An exception is pregnant adolescents, who would qualify for ART regardless of $\mathrm{CD}^{+}$count and time of infection. Measures to address HIV testing and access to care in children and adolescents are imperative.

\section{Combination ART and monitoring}

Table 1 tabulates the indications for ART initiation in adolescents. Table 2 describes first-, second- and third-line regimens currently used in adolescents. 
Table 2. ART regimens in ALHIV

\begin{tabular}{|c|c|}
\hline \multicolumn{2}{|l|}{ First-line regimen } \\
\hline Weight $<40 \mathrm{~kg}$ or age $<15 \mathrm{y}$ & $\mathrm{ABC}+3 \mathrm{TC}+\mathrm{EFV}^{*}$ \\
\hline Weight $\geq 40 \mathrm{~kg}$, age $\geq 15 \mathrm{y}$ and Tanner stage $\geq 3$ & $\begin{array}{l}\text { Fixed-dose combination (FDC): }{ }^{\dagger} \text { TEE } \\
\left(\mathrm{TDF}+\mathrm{FTC}^{\ddagger}+\mathrm{EFV}\right)\end{array}$ \\
\hline \multicolumn{2}{|l|}{ Pregnant adolescents } \\
\hline Age $>12$ y and weight $>40 \mathrm{~kg}$ & $\begin{array}{l}\mathrm{FDC} \mathrm{TEE}^{\dagger} \\
\mathrm{TDF}+3 \mathrm{TC} / \mathrm{FTC}+\mathrm{EFV} \text { (individual drugs } \\
\text { can be given and nevirapine can replace } \\
\text { EFV) }\end{array}$ \\
\hline \multicolumn{2}{|l|}{ Second-line regimen } \\
\hline $\begin{array}{l}\text { If first-line regimen was: } \\
\mathrm{ABC} / \mathrm{TDF}+3 \mathrm{TC} / \mathrm{FTC}+\mathrm{EFV}\end{array}$ & $\begin{array}{l}\text { Recommended second-line regimen: } \\
\mathrm{AZT}+3 \mathrm{TC}+\mathrm{LPV} / \mathrm{r}\end{array}$ \\
\hline \multicolumn{2}{|l|}{ Third-line regimen } \\
\hline Failing second-line regimen & $\begin{array}{l}\text { Consult a specialist } \\
\text { Regimen should be based on genotype } \\
\text { resistance testing and expert opinion with } \\
\text { supervised care } \\
\text { Access to third-line ART managed centrally } \\
\text { by the National Department of Health Third } \\
\text { Line Committee, email jamalk@health.gov.za }\end{array}$ \\
\hline \multicolumn{2}{|c|}{ 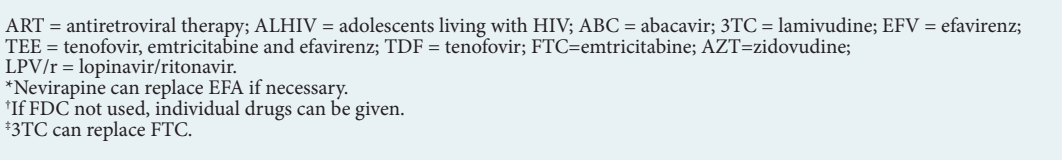 } \\
\hline
\end{tabular}

Monitoring of clinical, immunological and virological indicators on ART for adolescents is the same as for children. In addition, given the high risks of poor adherence and virological failure in this group, 6-monthly viral load (VL) testing should be considered.

\section{Outcomes on ART}

Longitudinal cohorts, mainly from wellresourced settings, report good clinical health with weight, height and body mass index approximating population norms. ${ }^{[5]}$ Reductions in mortality rates of up to $76 \%$ in PHIV children and adolescents receiving ART have been reported in well-resourced settings. ${ }^{[6]}$ All-cause mortality rates are similar when adolescents ( 9 - 19 years) and young adults receiving ART (20 29 years) are compared in reports from sub-Saharan Africa. ${ }^{[7,8]}$ Immunologically, cohorts from resource-rich and resourcelimited settings demonstrate robust $\mathrm{CD} 4^{+}$ improvement on ART, sustained to at least 5 years of follow-up. ${ }^{[6,8]}$ Adolescents, however, generally have lower virological suppression rates (HIV VL $<400$ copies/mL) on ART compared with adults. Suppression rates range between $27 \%$ and $78 \%$ in longitudinal cohorts with low rates in both PHIV and non-PHIV adolescents in
sub-Saharan Africa. ${ }^{[8-10]}$ Table 3 describes challenges with ART that are unique to

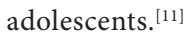

\section{Adherence}

Adolescence is a period of physical, sexual, emotional and psychological change associated with developing autonomy, increased impulsivity and risk taking, increased peer influence and potentially reduced parental oversight. Poor adherence in adolescence has been described in many chronic conditions including diabetes, asthma, cystic fibrosis and HIV. Poor adherence may be related to a number of factors including: simple lifestyle barriers such as forgetting or struggling to fit ART into a busy school and extramural schedule; medication-related factors such as complex twice-daily regimens with high pill burdens; drug-drug interactions, and side-effects; patient-related factors such as treatment fatigue, lack of disclosure to the adolescent and by the adolescent to others, fear of stigma, unresolved psychosocial problems or substance abuse; and socioeconomic constraints limiting access to the clinic.

Since both adherence and barriers may change over time, it is necessary to assess adherence and modifiable barriers at each visit and, together with the adolescent, tailor interventions to support adherence (Table 4). At each visit the following adherence reinforcements are necessary: identify and resolve any confusion with the regimen; manage any emerging drug sideeffects; enquire about changes in lifestyle and need for adjustments; and provide ongoing psychosocial counselling and management of new or unresolved issues. A multidisciplinary approach including social workers, nurse, mental health professionals and counsellors may be required where available.

\section{Approach to an adolescent with virological failure}

An elevated HIV VL is the most sensitive, though not necessarily specific, measure of non-adherence in HIV-infected patients as individuals with significant non-adherence will have detectable VLs. However, highly adherent individuals may have elevated VLs as a result of drug resistance, inappropriate regimens, drug interactions or incorrect doses. VL blips are defined as an unexplained VL between 50 and 1000 copies/mL with VL suppression on repeat sampling, and are of limited clinical significance. Virological failure is defined as a $\mathrm{VL}>1000$ copies $/ \mathrm{mL}$ on two consecutive assays taken at least 1 month apart from a patient on ART for at least 6 months. Virological failure precedes immunological failure which, in turn, usually precedes clinical failure, and allows early detection of adherence problems potentially prior to development of resistance mutations. Table 5 outlines management of adolescents with virological failure.

Not all adolescents with virological failure will have developed resistance. Resistance is more likely in regimens containing nevirapine, efavirenz and lamivudine as single mutations confer high-level resistance to these drugs. Since cross-resistance between nevirapine and efavirenz and other non-nucleoside reverse-transcriptase inhibitor (NNRTI) drugs occurs, adolescents failing an NNRTI-based regimen need to be switched to the standard second-line regimen as soon as possible to prevent accumulation of additional NRTI and/ or NNRTI resistance mutations that may compromise NRTIs and second-generation NNRTIs like etravirine that could be used in later regimens. ${ }^{[12]}$ Adolescents can safely be switched to the second-line regimen without HIV drug-resistance testing (DRT) (if not available), as the resistance mutations are largely predictable if early switch occurs. ${ }^{[12]}$ Adolescents with virological failure on a protease inhibitor (PI)-based regimen can continue intensive adherence counselling for longer 
Table 3. Challenges of ART treatment in PHIV adolescents*

\begin{tabular}{|c|c|c|}
\hline Problem & Implication & Solution \\
\hline \multicolumn{3}{|l|}{ Physiological } \\
\hline Rapid growth and puberty & $\begin{array}{l}\text { Exposure to inadequate ART dose as a } \\
\text { result of growth }\end{array}$ & $\begin{array}{l}\text { Routine dose adjustment per weight and Tanner } \\
\text { stage assessment }\end{array}$ \\
\hline Weight stunting and delayed puberty & $\begin{array}{l}\text { Overdosage of ART with potentially } \\
\text { increased toxicity }\end{array}$ & $\begin{array}{l}\text { Routine dose adjustment per weight and Tanner } \\
\text { stage assessment }\end{array}$ \\
\hline $\begin{array}{l}\text { Orofacial motor abnormalities or lesions } \\
\text { (e.g. candidiasis, poor dentition) }\end{array}$ & $\begin{array}{l}\text { Difficulty with swallowing ART leading to } \\
\text { decreased adherence }\end{array}$ & $\begin{array}{l}\text { Select regimens with ART agents available in liquid } \\
\text { or powder formulations (e.g. AZT, 3TC, ABC), or } \\
\text { crushable or dissolvable, or allow the capsules to be } \\
\text { opened (e.g. ATV, DRV, EFV, FTC, TDF) } \\
\text { Note: co-formulated agents cannot be crushed }\end{array}$ \\
\hline Poor palatability & Decreased adherence & $\begin{array}{l}\text { Same as above; consider masking taste using soda, } \\
\text { juice, apple sauce }\end{array}$ \\
\hline \multicolumn{3}{|l|}{ Adverse effects } \\
\hline GI intolerance (e.g. nausea, diarrhoea) & Decreased adherence & $\begin{array}{l}\text { Take with meals } \\
\text { Alter timing of administration (e.g. night-time } \\
\text { dosing) } \\
\text { Anti-emetic, antidiarrhoeal agents } \\
\text { Consider alternative regimen }\end{array}$ \\
\hline $\begin{array}{l}\text { Central nervous system side-effects (e.g. } \\
\text { altered sensorium, dreams, headache) }\end{array}$ & Decreased adherence & $\begin{array}{l}\text { Alter timing of administration (e.g. night-time } \\
\text { dosing) } \\
\text { Consider alternative regimen }\end{array}$ \\
\hline Change in physical appearance & Decreased adherence & Consider alternative regimen \\
\hline
\end{tabular}

(e.g. scleral icterus with ATV, facial

lipoatrophy with $\mathrm{d} 4 \mathrm{~T}$ )

\section{Drug-drug interactions}

Rifampicin-based TB co-treatment with $\mathrm{LPV} / \mathrm{r}$

Hormonal contraceptives and ritonavir-

Suboptimal LPV levels

Suboptimal hormonal levels with increased risk of pregnancy

\section{Comorbid conditions}

Malaria, low nutritional status and advanced HIV disease

Increased risk of anaemia with certain ARVs (e.g. AZT)

Decreased adherence
Increased boosting with ritonavir or double dosing with $\mathrm{LPV} / \mathrm{r}$

For females using ritonavir-boosted PIs and combination hormonal contraceptives (pills, patches and rings) or progestin-only pills, the use of an alternative contraceptive method with dual contraceptive method use is recommended

Regular assessment of haemoglobin levels at initiation, 1 month, 3 months and then every 6 months or symptomatic

Simplified regimens, cognitive age-appropriate education, regimens with a high barrier to resistance

Simplified regimens, cognitive age-appropriate education, regimens with a high barrier to resistance

Cognitive impairment due to HIV infection

\section{Developmental stage}

Concrete thinking and emotional immaturity

periods to try to achieve virological suppression, as PIs have a high resistance barrier and are associated with less accumulation of NRTI resistance mutations even with high VLs $>30000$ copies $/ \mathrm{mL}^{\left[{ }^{[12]}\right.}$ Most patients with virological failure on a boosted PI will resuppress on this regimen with optimal adherence.

Where possible, it may be appropriate to have a specific clinic day with multidisciplinary team support for adolescents with adherence problems, virological failure and resistance.
In some cases virological failure secondary to poor adherence may prove intractable despite adherence interventions, and the resultant immunological and clinical failure could constitute a relative emergency. In such instances a period of inpatient directly observed therapy should be considered to stabilise the adolescent, identify critical clinical, psychosocial and mental health issues, and provide intensive interventions. ${ }^{[13]}$ This should only be done in a multidisciplinary team setting in consultation with the adolescent and caregiver. 


\section{Table 4. Strategies to address non-adherence in HIV-infected adolescents}

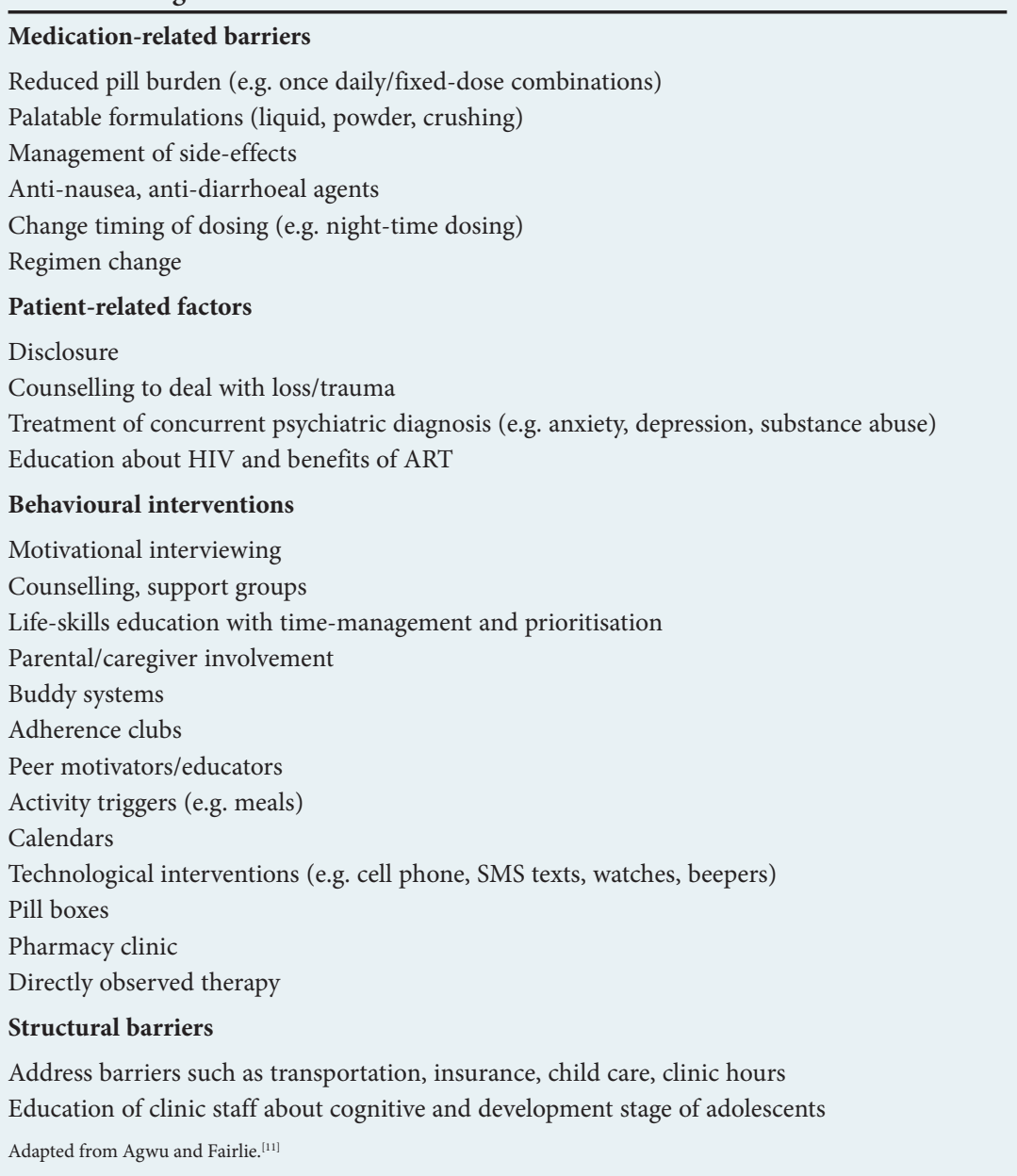

\section{Indications for HIV DRT}

The following are suggested criteria for DRT in adolescents: failing an NNRTI-based regimen based tuberculosis (TB) co-treatment). To optimise results, DRT should be done only if $\mathrm{VL} \geq 1000$ copies/mL; and if the adolescent has received ART for at least the past 4 weeks. Unfortunately it may not be possible to ensure adherence, and thus drug pressure, at the time of DRT if the adolescent claims adherence to be good. This will limit the interpretability of DRT as the resistant viral subpopulation may not be at adequate levels required for the DRT. The current DRT and all previous DRTs need to be combined with the treatment history to guide new regimen choices in treatmentexperienced adolescents.

\section{Drug-drug interactions}

Table 6 summarises the most important drug-drug interactions in children and adolescents. It is advisable to consult an up-to-date medicines formulary and available online resources (www.hivdruginteractions.org) prior to the prescription of any new agent where there is uncertainty about potential drug interactions.

\section{ART side-effects and toxicities}

Table 7 highlights the most significant sideeffects and toxicities in adolescents. The clinician needs to be aware of the risks of using tenofovir in adolescents $<15$ years of age and $<40 \mathrm{~kg}$ weight, with a low glomerular filtration rate (GFR) and Tanner staging of $\leq 3$. Gynaecomastia, which is common in pubertal adolescent males in general, may be associated with efavirenz; careful management to avoid psychological distress and subsequent adherence problems is required.

Table 5. Management of VL results in adolescents

\begin{tabular}{|c|c|}
\hline VL & Response \\
\hline Lower than detectable limit & $\begin{array}{l}\text { Congratulations! Adherence support/reinforcement as needed } \\
\text { Continue annual VL monitoring }\end{array}$ \\
\hline$<400$ copies/mL & Annual VL monitoring and adherence support \\
\hline $400-1000$ copies $/ \mathrm{mL}$ & $\begin{array}{l}\text { Step-up adherence package } \\
\text { Repeat VL in } 6 \text { months }\end{array}$ \\
\hline $\begin{array}{l}>1000 \text { copies } / \mathrm{mL}- \\
\text { virological failure }\end{array}$ & $\begin{array}{l}\text { Adherence counselling/review } \\
\text { Full review of ART history including PMTCT, past regimens (duration and virological response), current regimen } \\
\text { duration and response, } \mathrm{CD} 4^{+} \text {count and clinical stage } \\
\text { Repeat VL in } 3 \text { months } \\
\text { - If }<400 \text {, return to routine } 6 \text { - } 12 \text {-monthly monitoring } \\
\text { - If } 400 \text { - } 1000 \text {, continue step-up adherence and repeat VL after } 6 \text { months } \\
\text { - If NNRTI regimen and VL }>1000 \text { despite stepped-up adherence, switch to second-line therapy after adherence ensured } \\
\text { - If PI regimen and VL }>1000 \text { but }<30000 \text { despite stepped-up adherence, continue with same regimen while } \\
\text { monitoring VL every } 3 \text { months } \\
\text { - Continue stepping up adherence and consult an expert } \\
\text { - If PI regimen and VL }>30000 \text {, refer to an expert for further management }\end{array}$ \\
\hline
\end{tabular}


Table 6. Antiretroviral drug interactions for agents commonly used for the management of adolescents living with HIV

\begin{tabular}{|c|c|c|c|c|}
\hline Drug class & Drug & ARV interacts & Effect of interaction & Management of interaction \\
\hline \multirow[t]{5}{*}{ Antibiotics } & \multirow[t]{2}{*}{ Rifampicin } & $\mathrm{LPV} / \mathrm{r}$ & Reduced level of EFV & $\begin{array}{l}\text { Superboost with additional RTV, to bring } \\
\text { the ratio of LPV:RTV to 1:1 or double the } \\
\mathrm{LPV} / \mathrm{r} \text { dose if RTV not available }\end{array}$ \\
\hline & & NVP & $\begin{array}{l}\text { Cumulative toxicity, may have } \\
\text { reduced NVP levels }\end{array}$ & Avoid concurrent use \\
\hline & \multirow[t]{2}{*}{ Clarithromycin } & EFV & $\begin{array}{l}\text { Reduced level of } \\
\text { clarithromycin }\end{array}$ & $\begin{array}{l}\text { Avoid concurrent use; consider } \\
\text { azithromycin as an alternative }\end{array}$ \\
\hline & & $\mathrm{AZT}$ & $\begin{array}{l}\text { Reduced level of AZT if } \\
\text { administered together }\end{array}$ & $\begin{array}{l}\text { Give clarithromycin and AZT at least } \\
2 \text { hours apart }\end{array}$ \\
\hline & Aminoglycosides & TDF & Cumulative renal toxicity & $\begin{array}{l}\text { Avoid concurrent use where possible; } \\
\text { monitor renal function and discuss with } \\
\text { expert where necessary }\end{array}$ \\
\hline Antifungals & Fluconazole & NVP & $\begin{array}{l}\text { Elevated NVP levels, } \\
\text { may have cumulative } \\
\text { hepatotoxicity }\end{array}$ & Monitor for NVP side-effects \\
\hline \multirow[t]{2}{*}{ Anticonvulsants } & $\begin{array}{l}\text { Carbamazepine } \\
\text { Phenytoin } \\
\text { Phenobarbitone }\end{array}$ & PIs, NNRTIs & Altered ART drug levels & $\begin{array}{l}\text { Valproate/lamotrigine are preferred } \\
\text { anticonvulsants in combination with ART }\end{array}$ \\
\hline & Valproate & $\mathrm{AZT}$ & Increased AZT level & $\begin{array}{l}\text { Monitor for AZT side-effects; consider } \\
\text { alternatives }\end{array}$ \\
\hline \multirow[t]{2}{*}{ Psychotropic drugs } & $\begin{array}{l}\text { Benzodiazepines (NB } \\
\text { midazolam, triazolam) }\end{array}$ & PIs & $\begin{array}{l}\text { Delayed clearance of the } \\
\text { benzodiazepine may result in } \\
\text { increased sedation }\end{array}$ & Lorazepam is the preferred agent \\
\hline & $\begin{array}{l}\text { Fluoxetine } \\
\text { Paroxetine }\end{array}$ & PIs & $\begin{array}{l}\text { Drug levels may increase to } \\
\text { dangerous level }\end{array}$ & $\begin{array}{l}\text { Avoid concurrent use - citalopram } \\
\text { preferred. }\end{array}$ \\
\hline Contraceptives & $\begin{array}{l}\text { Oral contraceptives } \\
\text { (COCs, POPs) }\end{array}$ & PIs, NNRTIs & $\begin{array}{l}\text { Contraceptive efficacy may } \\
\text { be reduced }\end{array}$ & $\begin{array}{l}\text { Avoid concurrent use. Strongly reinforce } \\
\text { condom use and advise on alternative } \\
\text { methods (IUCD or injectable) }\end{array}$ \\
\hline \multirow[t]{5}{*}{ Others } & Warfarin & NNRTIs, PIs & Warfarin level altered & $\begin{array}{l}\text { Monitor INR closely and adjust warfarin } \\
\text { dose accordingly }\end{array}$ \\
\hline & $\begin{array}{l}\text { Corticosteroids } \\
\text { (NB: fluticasone, } \\
\text { budesonide) }\end{array}$ & PIs & $\begin{array}{l}\text { Increased level of } \\
\text { corticosteroids }\end{array}$ & $\begin{array}{l}\text { Monitor closely for systemic effects of } \\
\text { corticosteroids; consider dose reduction }\end{array}$ \\
\hline & $\begin{array}{l}\text { Simvastatin and } \\
\text { lovastatin }\end{array}$ & PIs & $\begin{array}{l}\text { Increased level - may lead to } \\
\text { dangerously toxic levels }\end{array}$ & $\begin{array}{l}\text { Consider substitution with low-dose } \\
\text { atorvastatin (in consultation with an expert) }\end{array}$ \\
\hline & Ergotamine & PIs & $\begin{array}{l}\text { Increased level, may lead to } \\
\text { toxicity }\end{array}$ & Avoid concurrent use \\
\hline & St John's wort & PIs, NNRTIs & $\begin{array}{l}\text { Reduces levels of } \\
\text { antiretroviral agents }\end{array}$ & Avoid concurrent use \\
\hline
\end{tabular}

\section{Disclosure to adolescents}

In order to fulfil their developing autonomy adolescents require accurate information regarding their health, including their HIV status. WHO recommends that disclosure occurs before 12 years of age, but this needs to be applied to each individual context. ${ }^{[14]}$ Consideration of the maturity and level of insight is essential. A child who enquires about their treatment and their health indicates a desire for further information and a need to start the disclosure process. Disclosure should be complete long before sexual activity begins. Disclosure may result in improved adherence, acceptance of the diagnosis and improved clinical outcomes. ${ }^{[15]}$ Moreover, disclosure of maternal HIV status to the child may strengthen the relationship and build trust between mother and child. ${ }^{[16]}$

Caregivers need supportive counselling in order to prepare them for the disclosure process. Disclosure is not a once-off event, but a process, built on a foundation of health education, aiming to teach the child about maintaining their health, understanding their condition and beginning to take ownership of their own healthcare. Disclosure is never urgent, and is best done by the caregiver after adequate preparation. Many tools are available for facilitating 


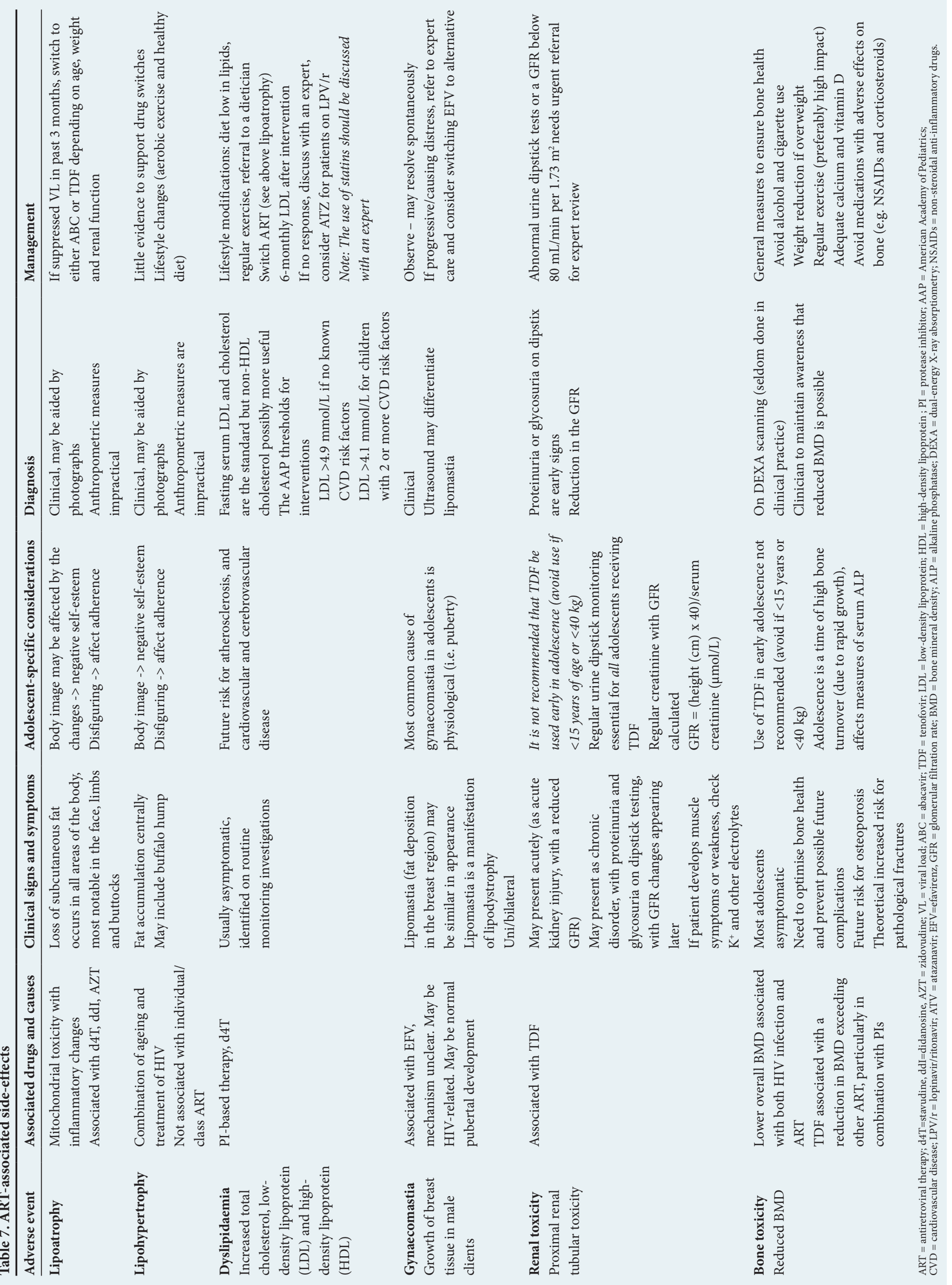


disclosure, including talking books, picture books and comic books, some aimed at educating the adolescent, others guiding the caregiver. Adolescents also require support in connection with disclosing to sexual partners, friends, parents or any other individual, if and when this becomes desirable.

\section{Transition to adult care}

Transition of adolescents from child-focused care to adult-focused care may involve physical transfer to a different clinical space or may be a developmental shift with the adolescent moving from a supported to an independent, autonomous role within the same clinic. Regardless, planning to ensure safe and successful transition is required, as transition may be accompanied by significant anxiety and may result in disruption of care. All adolescents who transition to adult care must have undergone a disclosure process with ongoing support, information and reassurance. ${ }^{[17]}$ Full communication to the adult-care practitioner, of all previous medical, sexual and reproductive health and psychosocial history, is essential. Ongoing attention to sexual and reproductive health needs, particularly access to contraception, is important for the transitioning adolescent.

In settings receiving these transitioning youth, familiarity with the complexities of managing HIV-infected youth from a medical and psychosocial perspective, a multidisciplinary team with co-ordination of all aspects of care, and appropriate linkage to other services including sexual and reproductive health services, psychological and psychiatric care are required. ${ }^{[17]}$

In conclusion, although many adolescents living with HIV have good outcomes on ART, adolescence is a high-risk period for nonadherence and associated virological failure. Clinicians need to be aware of adolescent-associated problems, and mechanisms to assist this population with a successful transition to adult care.

\section{References}

1. UNAIDS. Global Report: UNAIDS Report on the Global AIDS Epidemic 2013. Geneva: UNAIDS, 2013

2. Shisana O, Rehle T, Simbayi L, et al. South African National HIV Prevalence, Incidence and Behaviour Survey, 2012. Cape Town: HSRC Press, 2014

3. Violari A, Cotton MF, Gibb DM, et al. Early antiretroviral therapy and mortality among HIV-infected infants. New Engl J Med 2008;359:2233. [http://dx.doi.org/10.1056/NEJMoa0800971]

4. Judd A, Ferrand RA, Jungmann E, et al. Vertically acquired HIV diagnosed in adolescence and early adulthood in the United Kingdom and Ireland: Findings from national surveillance. HIV Medicine 2009;10(4):253-256.

5. Dollfus C, Chenadec JL, Faye A, et al. Long-term outcomes in adolescents perinatally infected with Dollfus C, Chenadec JL, Faye A, et al. Long-term outcomes in adolescents perinatally infected with
HIV-1 and followed up since birth in the French Perinatal Cohort (EPF/ANRS CO10). Clin Infect Dis HIV-1 and followed up since birth in the French Perinat
2010;51(2):214-224. [http://dx.doi.org/10.1086/653674]

6. Patel K, Hernan MA, Williams PL, et al. Long-term effectiveness of highly active antiretroviral therapy on the survival of children and adolescents with HIV infection: A 10-year follow-up study. Clin Infect Dis 2008;46(4):507-515

7. Bakanda C, Birungi J, Mwesigwa R, et al. Survival of HIV-infected adolescents on antiretroviral therapy in Uganda: Findings from a nationally representative cohort in Uganda. PloS One 2011;6(4):e19261 [http://dx.doi.org/10.1371/journal.pone.0019261]

8. Nglazi MD, Kranzer K, Holele P, et al. Treatment outcomes in HIV-infected adolescents attending a community-based antiretroviral therapy clinic in South Africa. BMC Infectious Diseases 2012;12:21. [http://dx.doi.org/10.1186/1471-2334-12-21]

9. Nachega JB, Hislop M, Nguyen $\mathrm{H}$, et al. Antiretroviral therapy adherence, virologic and immunologic outcomes in adolescents compared with adults in southern Africa. J Acquir Immune Defic Syndr 2009;51(1):65-71. [http://dx.doi.org/10.1097/qai.0b013e318199072e]

10. Van Cutsem G, Knight L, Abrahams M, et al. Outcomes in children, adolescent, youth and adults on . Van Cutsem G, Knight L, Abrahams M, et al. Outcomes in children, adolescent, youth
ART in Khayelitsha. AIDS 2010 - XVIII International AIDS Conference; Vienna, 2010.

11. Agwu AL, Fairlie L. Antiretroviral treatment, management challenges and outcomes in perinatally Agwu AL, Fairlie L. Antiretroviral treatment, management challenges and outcomes in perinatally
HIV-infected adolescents. J Int AIDS Soc 2013;16(1):18579. [http://dx.doi.org/10.7448/ias.16.1.18579] 12. PENPACT Study Team, Babiker A, Castro nee Green H, Compagnucci A, et al. First-line antiretroviral therapy with a protease inhibitor versus non-nucleoside reverse transcriptase inhibitor and switch at higher versus low viral load in HIV-infected children: An open-label, randomised phase 2/3 trial. Lancet Infect Dis 2011;11(4):273-283. [http://dx.doi.org/10.1016/ s1473-3099(10)70313-3]

13. Purdy JB, Freeman AF, Martin SC, et al. Virologic response using directly observed therapy in adolescents with HIV: An adherence tool. Journal of the Association of Nurses in AIDS Care: JANAC 2008; $19(2): 158-165$

14. World Health Organization. Guideline on HIV disclosure counselling for children up to 12 years of age. Geneva: World Health Organization, 2011.

15. Calabrese SK, Martin S, Wolters PL, Toledo-Tamula MA, Brennan TL, Wood LV. Diagnosis disclosure, medication hiding, and medical functioning among perinatally infected, HIV-positive disclosure, medication hiding, and medical functioning among perinatally infected, HIV-positive
children and adolescents. AIDS Care 2012;24(9):1092-1096. [http://dx.doi.org/10.1080/09540121. children and

2012.699670]
16. Kennedy DP, Cowgill BO, Bogart LM, et al. Parents' disclosure of their HIV infection to their children Kennedy DP, Cowgill BO, Bogart LM, et al. Parents' disclosure of their HIV infection to their children
in the context of the family. AIDS Behav 2010;14(5):1095-1105. [http://dx.doi.org/10.1007/s10461in the context of the family. AIDS Behav 2010;14(5):1095-1105. [http://dx.doi.org/10.1007/s10461-
010-9715-y] 17. HIVguidelines.org. Transitioning HIV-Infected Adolescents into Adult Care. http://
wwwhivguidelinesorg/clinical-guidelines/adolescents/transitioning-hiv-infected-adolescents-intoadult-care/ (accessed 15 April 2014). 